\title{
Development of Materials for Naval, Fluvial and Military Applications
}

Desarrollo de Materiales para Aplicaciones Marítimas, Fluviales y Militares

DOI: https://doi.org/10.25043/19098642.164
Fabio A. Suárez-Bustamante ${ }^{1}$

Orlando D. Barrios-Revollo ${ }^{2}$

Anderson Valencia ${ }^{3}$

Juan P. Hernández-Ortiz ${ }^{4}$

\begin{abstract}
A platform to design composite materials of a polymeric matrix, that are specifically for military applications on fluvial and naval navigation, has been developed using energy dissipation and storage mechanisms. Our composites are designed to generate synergy between the dissipation capacities of ceramics and high-performance fibers, which are used as the reinforced material in the lightweight laminates. The composite design is combined with processing tools and advanced characterization techniques that result in laminates with reliability, traceability and quality. The platform begins with the identification of energy dissipation mechanisms and the detailed characterization of the polymeric resin. It includes the Time - Temperature - Transformation Diagram (TTT- Diagram) that supplies the optimal processing conditions. Our designs open new paths for military applications including a wide spectrum of protective systems together with geometric versatility, high mechanical resistance and reliability.
\end{abstract}

Key words: Composite Materials, Materials Design, Military Applications, Impact Energy Dissipation Mechanisms, Naval and Fluvial Applications.

\section{Resumen}

Utilizando los múltiples mecanismos de disipación de la energía de impacto a alta velocidad, hemos desarrollado una plataforma de diseńo de materiales compuestos de matriz polimérica, especiales para aplicaciones militares en navegación fluvial y marítima. Nuestros compuestos pretenden hacer sinergia entre las capacidades de disipación de cerámicos y fibras de alto desempeño, los cuales son utilizados como los elementos de refuerzo en los laminados de bajo peso. El diseńo del material es combinado con herramientas de procesamiento y técnicas avanzadas de caracterización que resultan en laminados consistentes de alta repetibilidad, trazabilidad y alta calidad. La plataforma parte de la identificación de los mecanismos de disipación y de una caracterización detallada de la resina polimérica, el cual incluye un diagrama de Tiempo-Temperatura-Transformación que provee las condiciones óptimas de procesamiento. Nuestros diseños abren rutas novedosas para aplicaciones militares, los cuales incluyen amplios portafolios de protección, versatilidad geométrica, resistencia mecánica y confiabilidad.

Palabras claves: Materiales Compuestos, Diseño de Materiales, aplicaciones Militares, Mecanismos de Disipación de Energía de Impacto, Aplicaciones Navales y Fluviales.

Date Received: July $7^{\text {th }} 2017$ - Fecha de recepción: Julio 7 de 2017

Date Accepted: November 14 2017 - Fecha de aceptación: Noviembre 14 de 2017

\footnotetext{
${ }^{1}$ Department of Materials, Faculty of Mines, Universidad Nacional de Colombia. Medellín, Colombia. Email: fasuarez@unal.edu.co

${ }^{2}$ Department of Materials, Faculty of Mines, Universidad Nacional de Colombia. Medellín, Colombia. Email: odbarriosr@unal.edu.co

${ }^{3}$ DynaComp S.A.S. Calle 80 Sur \# 47 D163 - Bodega 1, Sabaneta, Colombia. Email: anderson.valencia@dynacomp.com.co

${ }^{4}$ Institute for Molecular Engineering, University of Chicago, Chicago, IL, USA. Email: jphernandezo@wisc.edu
} 


\section{Ballistic Materials and Design Trends}

From the beginnings of the human race, man has made elements for his personal protection. Leather, wood and some metals were used as materials to fabricate helmets, body-armor, shields and other items. Today, metals are used for these purposes and intensive research is done to improve their ballistic performance. Steel, aluminum and titanium alloys are widely used for these applications [1-11]. Nevertheless, metals are heavier than polymers and some ceramics, limiting their application for lightweight body and structural armors for land, air and water vehicles. In addition, metal processing requires large quantities of energy. Ceramics, polymers and composites have become the new option to avoid these restrictions [12-15]. However, each material and composite faces challenges due to the constant improvements in the development of projectiles and weapons and in the specific conditions of new applications.

According to Grujicic [16], fiber-based composites were used for the first time in body-armor in the Korean war. They were constructed with nylon fabric and E-glass fibers within an ethyl cellulose matrix composite. Currently, high performance polymeric fibers such as polyaramids (Kevlar[17,18], Twaron [18,19], Technora $[18,20])$, highly oriented and crystallized ultra high molecular weight polyethylene (UHMWPE) (Spectra [18, 21] and Dyneema [18, 22]), polybenzobis-oxazole PBO (Zylon $[18,23]$ ) and polypyridobisimi-dazole PIPD (M5) [18], are widely used for ballistic composites. Under tension, these materials differ significantly from the nylon fibers, having a high absolute stiffness, extremely high specific strength, and quite low $(<4 \%)$ strains-tofailure. These fibers essentially behave in tension as rate-independent linear elastic materials. When they are subjected to transversal compression tests they show large plastic deformations similar to the strains measured for the nylon and without having significant losses in their tensile load capacity. This behavior radically differs from carbon and glass fibers, which tend to flake under a tensile load condition.
The ballistic performance of polymeric fibers is evaluated according to their capacity to absorb the kinetic energy from a projectile and how fast they can disperse that energy to their surroundings, avoiding local conditions for failure [16]. The last aspect is governed by the sound speed in the fiber $c=\sqrt{E / \rho}$ where $E$ is Young's modulus and $\rho$ the material density) $[16,18]$.

UHMWPE and aramid fibers (like KEVLAR) had become popular reinforcement materials due to their high performance. They had replaced traditional ones like glass and nylon fibers [16]. However, in extreme applications, where a NIJ-III is required or IV protection levels, ceramic materials are preferred. Among them, alumina (Al2O3) is widely used due to its low manufacturing cost and the multiple options to process them, i.e. slip casting, pressing or injection molding. According to Medvedovski special and expensive equipment is not needed for their processing [12, 24-26]. These materials are characterized by good mechanical properties and a relative low density $\left(3.95 \mathrm{~g} / \mathrm{cm}^{3}\right.$ for the alumina; aluminum density is about $2.7 \mathrm{~g} / \mathrm{cm}^{3}$ ).

In this paper, we are describing a platform to design composite materials of polymeric matrix that are special for military applications. Our platform integrates lightweight laminar composite materials, designed from their impact energy dissipation and storage mechanisms, with stateof-the-art manufacturing process and material characterization techniques.

\section{Energy Dissipation and Storage Mechanisms under Impact}

There are multiple mechanisms that have been identified to stop a projectile. Some of them are associated to the energy absorption during the localized and progressive damage of the target material while projectile pass through it, i.e. matrix cracking, shear delamination, compressioncutting, tensile-cutting, hydrostatic compression, melting (Karamis' zones), adhesion and abrasion [27-32]. Other mechanisms are associated to the temporary energy storage, the elastic deformation 
and the movement of the cone [30,33]. The presence and the incidence of all these mechanisms are conditioned by: the projectile and target materials $[1,18,24-38]$; the geometrical characteristics of the projectile nose $[1,37,38]$; the properties of the materials and the configuration of the composites (as laminar or layered structures, disperse particles in a matrix, oriented fibers in a matrix or porous mediums) [28, 30-33, 36-39]; impact angle and impact speed $[1,34]$ among others.

Polymer matrix composite materials with laminar structures are another kind of ballistic materials that combine a set of interesting mechanisms to stop a bullet. Gama and Gillespie [30-32] worked with a S-2 glass/SC15 composite and proposed a model based on a Quasi-Static Punch Shear Tests (QS-PST) to quantify and classify the energy dissipation into elastic and absorbed energies as a function of the penetration displacement and support span. The energy partition is based on the identification of the mechanisms that take place during the five phases of the bullet-penetration: (i) impact-contact and stress wave propagation; (ii) hydrostatic compression and local punch shear; (iii) shear plug formation under compressionshear; (iv) large deformation under tension-shear; and (v) end of penetration and structural vibration. Contrary to a dynamic ballistic impact, where typical bullets are engineered projectiles, flat nose cylinder projectiles were used, with the assumption that they are considered rigid bodies. Classical Ballistic Limit Analysis (CBLA) applies for rigid projectiles and establishes that the limiting velocity $V_{50}$, i.e. the velocity for which the probability that a projectile penetrates a target, is related with the impact velocity $V_{P}$, the residual velocity $V_{R}$ and the projectile mass $m_{p}$ :

$\frac{1}{2} m_{p} V_{l}^{2}-\frac{1}{2} m_{p} V_{R}^{2}=\frac{1}{2} m_{p} V_{50}^{2}+\frac{1}{2} m_{E} V_{R}^{2}$

Equation (1) establishes that the transferred energy to the target by the projectile in case of whole penetration $\left(V_{I}>V_{50}\right)$ equals the sum of the kinetic energy associated to $V_{50}$ and the kinetic energy of an equivalent mass $m_{E}$ that moves with residual velocity $V_{R}$. Consequently, $V_{R}$ is defined as follows
$V_{R}=\left(\frac{m_{p}}{m_{p}+m_{E}}\right)^{1 / 2}\left(V_{l}^{2}-V_{50}^{2}\right)^{1 / 2}$

$V_{R}=\alpha\left(V_{l}^{2}-V_{50}^{2}\right)^{1 / 2}$

This velocity can be estimated from the Lambert and Jonas equation [1] as

$V_{R}=\beta\left(V_{l}^{p}-V_{50}^{p}\right)^{1 / 2}$,

where $\beta$ and $p$ are fitting parameters. Equations (1) and (2) with experimental data for impact tests using different $V_{I}$ provide an estimation of the limiting velocity of a projectile-target system (see Fig. 1).

In the case where a complete projectile penetration occurs $V_{I} \rightarrow V_{50}$ and $V_{R}=0$. Therefore, it is possible to separate the kinetic energy transmitted to the target as the sum of three components: (i) absorbed energy by the target by several failure mechanisms, $E_{\text {absorbed; }}$; (ii) accumulated elastic energy, $E_{E-\text { Acum }}$; and (iii) kinetic energy associated to cone movement, $E_{K \text {-Come }}$. The energy transmitted to the target, $E_{50}$ is defined by,

$E_{50}=E_{\text {absorbed }}+E_{E-\text { Acum. }}+E_{K-\text { Come }}$

Elastic and kinetic energies are dissipated after the impact by mechanisms of structural vibration and viscous damping (mechanisms (v)). Some authors [30-33] consider these energy components as part of the energy absorbed by the system; however, this approximation is not satisfactory because a great amount of energy that is initially transmitted to the target is then transmitted to the environment and is not fixed or permanently stored by the material [30].

To estimate each contribution in $E_{50}$, an identification of the active mechanisms is performed using ballistic punch shear tests (Ballistic-PST) and a relationship is established with those mechanisms observed in QS-PST for the same ballistic system (target-projectile) [30]. From a systematic study of set of curves obtained from the QS-PST, Gama and Gillespie's team developed a quasi-static ballistic 
Fig. 1. Residual velocity $\mathrm{V}_{\mathrm{R}}$ as function of the impact velocity $\mathrm{V}_{\mathrm{I}}$, for a S-2Glass/SC15 layered composite with a target thickness $\mathrm{H}_{\mathrm{C}}=13,2 \mathrm{~mm}$ and a flat nose cylinder projectile made of steel with mass $\mathrm{m}_{\mathrm{p}}=13,8 \mathrm{~g}$ and diameter $\mathrm{D}_{\mathrm{p}}=12,7$ $\mathrm{mm}$ [30]

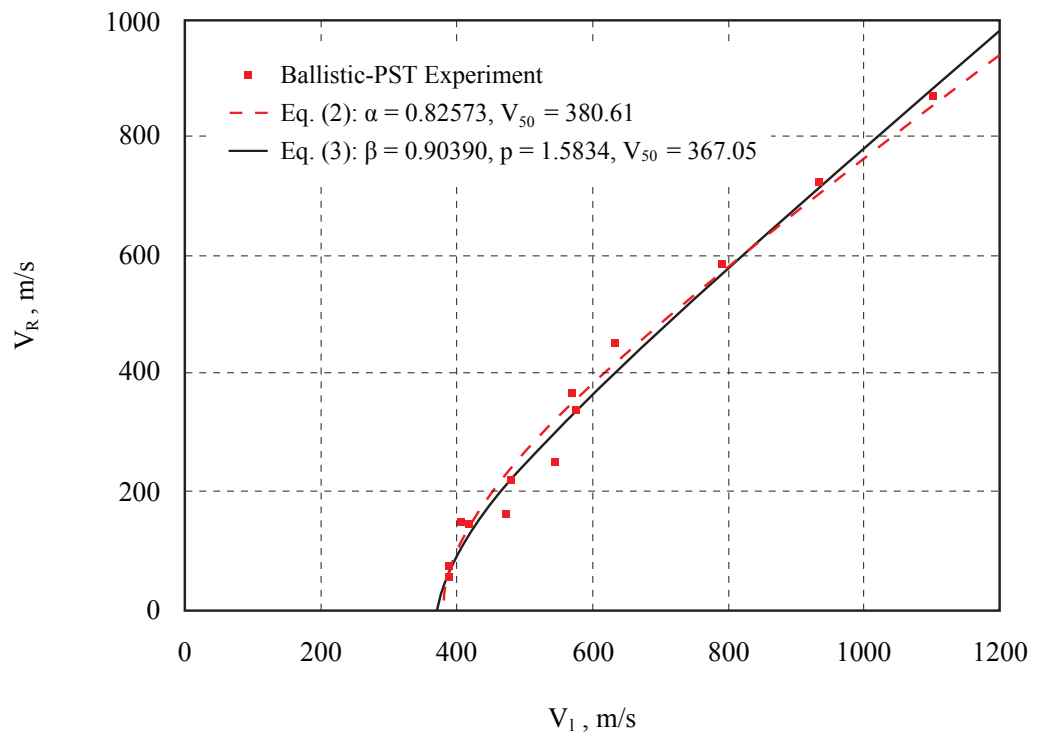

penetration model and a method to determine the ballistic limit $V_{50}$ for laminar composite materials [30-32]. We currently are working to enhance the applicability of this model to laminar composite materials reinforced with hard ceramic particles.

In the case of ceramic materials of high alumina content (alumina-mullite AM, or alumina containing mullite, zirconia and zircon ZAS) and heterogeneous reaction-bonded ceramics, failure mechanisms are linked with brittle fracture [24-26]. On the rear face, the affected impact region is characterized by coaxial and radial cracks generated by tensile stress (because of bending associate to the bulging) that give this area a cone shape (Fig. 2). Spalling is also observed. The size of the generated fragments varies in an extremely wide range from extra-fine powders (on the nanometer scale) up to big parts of the order of several centimeters (mesoscale). Sarva et al. [35] have discovered that this fine powder is generated by an erosive mechanism that erodes the projectile reducing its kinetic energy. This resulting powder is the combination of the projectile and target material. This erosive mechanism that is accompanied by an ejected flow is very efficient to reduce the kinetic energy of the projectile and its effect could be enhanced to vastly improve the ballistic efficiency of ceramic tiles by judiciously restraining them with membranes of polymeric composites or metal sheets.

An application that has a close relation with our composite materials is the case of lightweight laminate metallic matrix composite reinforced with ceramic particles. The work of Karamis at al. is one of the best in the field from the descriptive point of view of the ballistic impact phenomenon [27-29]. They have designed some composites materials of this kind using an Almatrix and alumina as a reinforcement element to defeat engineered projectiles $(7,62 \mathrm{~mm} \times 51$ $\mathrm{mm}$ Armour Piercing, AP) shot by a G3 assault rifle with an average impact velocity of 710 $\mathrm{m} / \mathrm{s}$. Targets are $15 \mathrm{~mm}$ thick and can stop this kind of projectiles. The ballistic material was manufactured by the combination of a process of hot compression and squeeze casting. Fig. 3 shows details of the impact zones of ballistic tests carried out for two different configurations of their laminate, where multiple energy dissipation mechanisms are identified.

Our polymeric matrix composite is designed to generate synergy between the matrix, the 
Fig. 2. Ceramic material. Energy Dissipation Mechanisms based in brittle fracture: spalling and radial and tangential cracking due to tensile stress. Projectiles are also deformed and their surfaces are abraded [24-26]

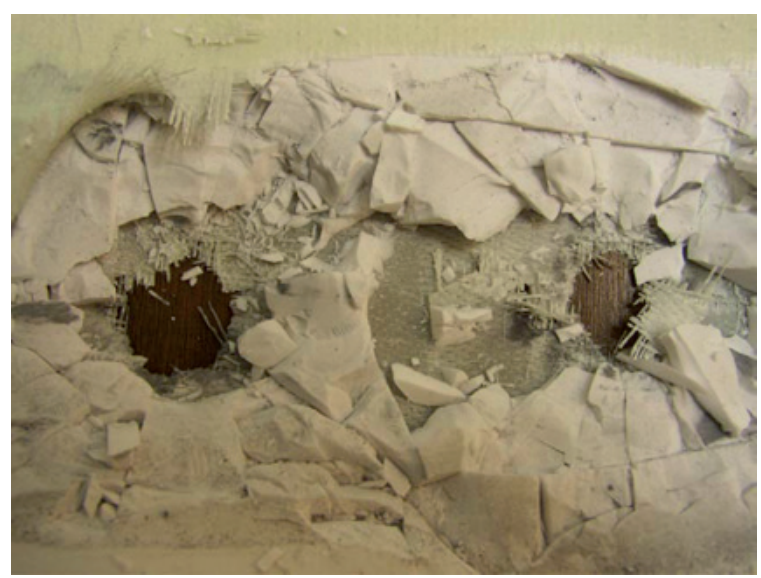

a) High content alumina and mullite ceramic (AM2). View of the rear face of the plate after being impacted by a projectil (NATO Ball FMJ 7.62x51mm). Backing material was removed

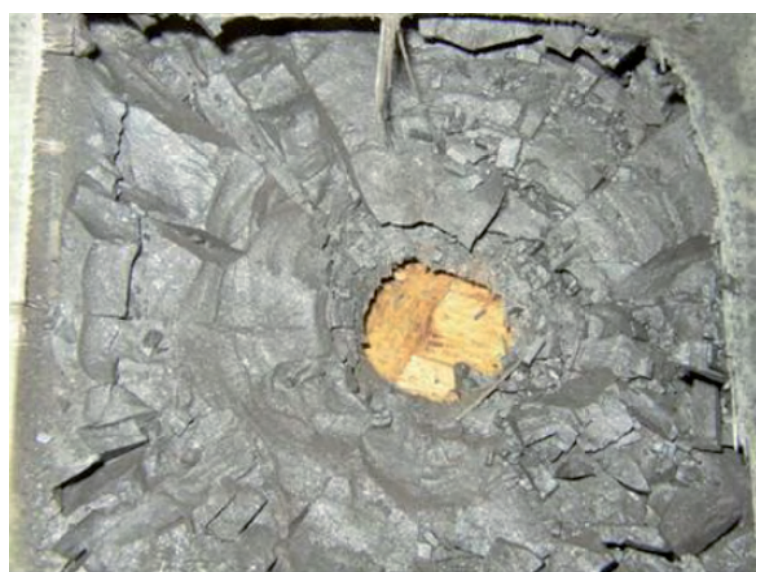

b) Biomophic ceramic (RBS) impacted by $7.62 \times 63 \mathrm{~mm}$ APM2 projectile

reinforcing fibers and ceramic particles. The mechanisms embedded in our composites are:

1. Elastic deformation of the main and secondary fibers in the impact zone.

2. Kinetic energy of the moving cone of the target.

3. Rupture or facture of fibers.

4. Cracking of the target matrix.

5. Delamination of the layers around impact zone.

6. Shear plug formation and compression of the layers in the contact zone just when projectile geometry is adequate.

7. Abrasion of the projectile surface (damage of the projectile skin).

Some of the individual contributions for these mechanisms have been estimated. We are currently working on the abrasive contribution of the particles. We are, however, able to provide a crude assessment of the energy involved in this complex phenomenon.

Fig. 3. Ceramic material. Energy Dissipation Mechanisms MMC - B Type Structure. Perforation left by projectile after its extraction [28]

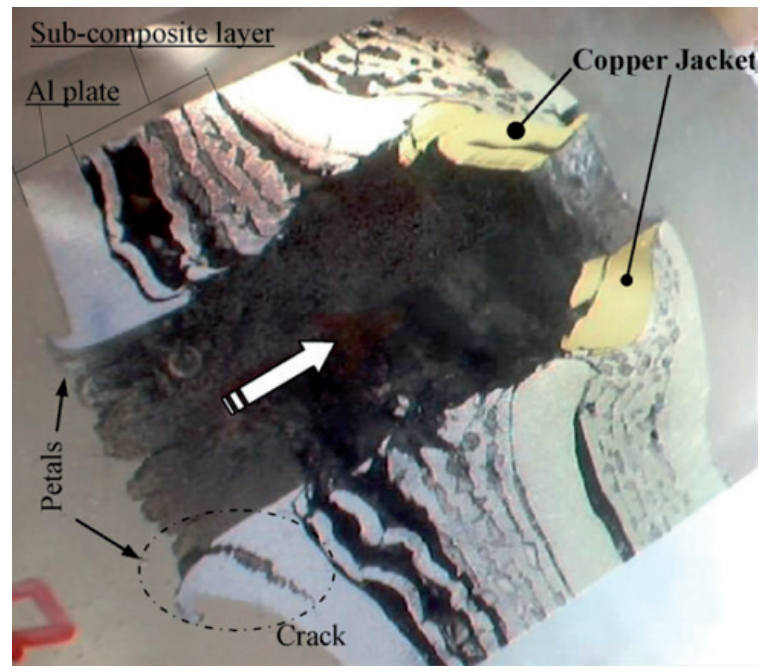

a) General view showing some failure mechanisms as petalling, swelling, delamination of layers, high strained regions by compression and shear, melting welding, bending and bulging

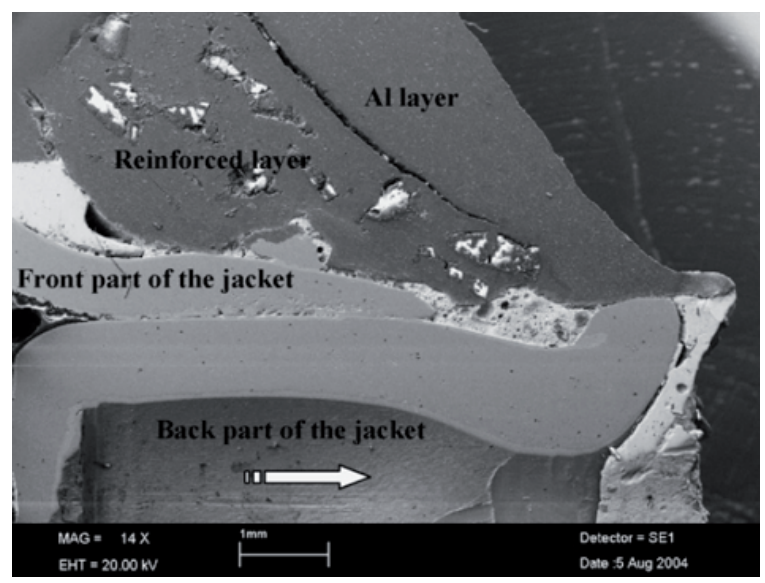

b) Detail of the projectile output: compressed and highdeformed layers, mixing regions, high deformation and geometrical changes of the peeling cap 


\section{Laminar Composites}

We fabricated polymeric matrix composite materials reinforced with hard particles and high performance fibers using a state-of-the-art vacuum assisted infusion molding. Epoxy resins and a polyester based-resin are used as the polymeric matrices. Three kinds of high performance fibers were used as reinforcement: glass, Kevlar and carbon fibers. These fibers were provided as woven fabrics in four different configurations as shown in Fig. 4. Two kinds of hard particles are used as the additional reinforcement that provides abrasive and hardness characteristics to the composite. The laminates are thin tiles of laminar composites, are light and stiff and made with a thickness of approximately $1 \mathrm{~mm}$. The infusion resulted in high reproducible laminates with a standard deviation of $0.3 \mathrm{~mm}$ in the thickness.

Fig. 5 shows details of some setups used to manufacture samples by vacuum assisted infusion techniques. Different configurations were used to explore how the vacuum line and the in/out points can affect the integrity of the manufactured samples. These types of experimental exercises have permitted the identification of the more relevant elements to be considered during the manufacture of the composites and how the assemblies can be simplified without affecting the quality of the products and reducing costs and the negative impact in the environment. Fig. 6 shows some samples manufactured by these techniques.

\section{Characterization}

Fig. 7 shows images obtained by a stereoscopic and optical microscopy of the cross section of four samples of laminar composites. These pictures reveal important details of their specific configurations: size and shape of the branches of fibers, fibers distribution, defects (as pores for instance), areal percentage of components, cross sections of the composite, spaces occupied by the matrix and composite homogeneity.

A primary characterization of some ballistic products was carried out at the Laboratorio
Fig. 4. Kinds of fabrics and fibers used as reinforcement

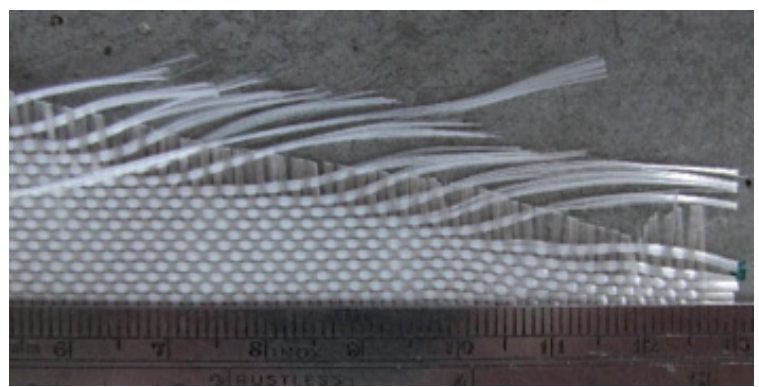

a) E-Glass Fiber fabric, density: $257 \mathrm{~g} / \mathrm{m}^{2}$

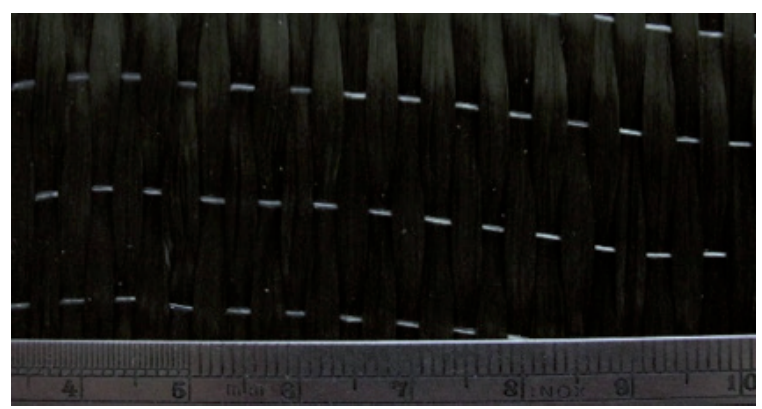

b) Unidirectional Carbon Fiber fabric

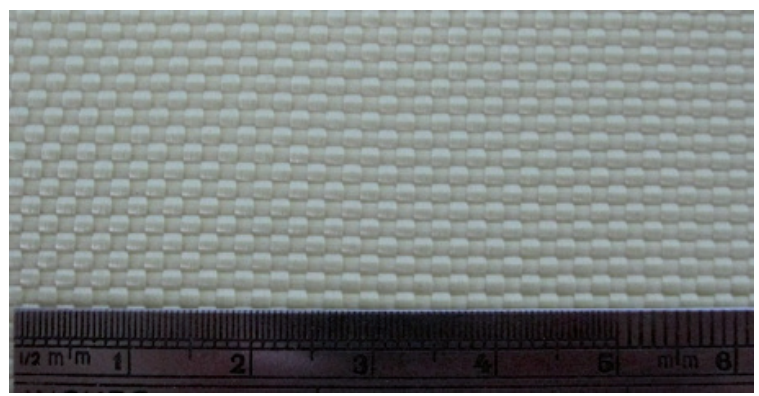

c) Kevlar woven fabric, density: $257 \mathrm{~g} / \mathrm{m}^{2}$

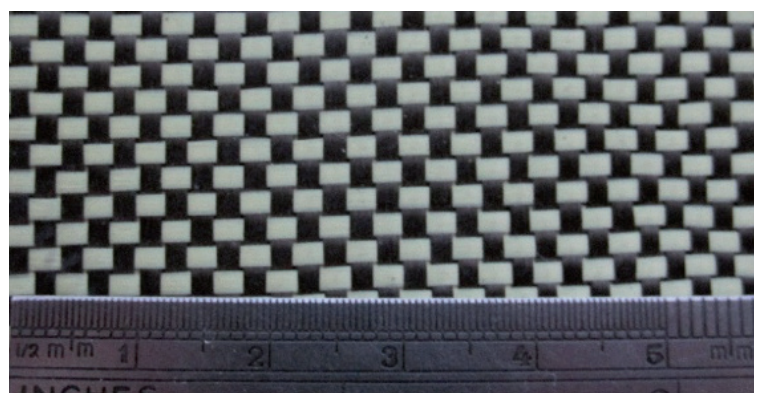

d) Mixed woven fabric: Kevlar and Carbon Fibers, density: $185 \mathrm{~g} / \mathrm{m}^{2}$

de Caracterización de Materiales (Material Classification Laboratory) of the Universidad Nacional de Colombia using Scanning Electron Microscopy (SEM). Fig. 8 shows some geometrical characteristics of the fibers of the evaluated 
Fig. 5. Examples of two Infusion Systems designed to evaluate the flexibility of the process and identify some of its relevant variables

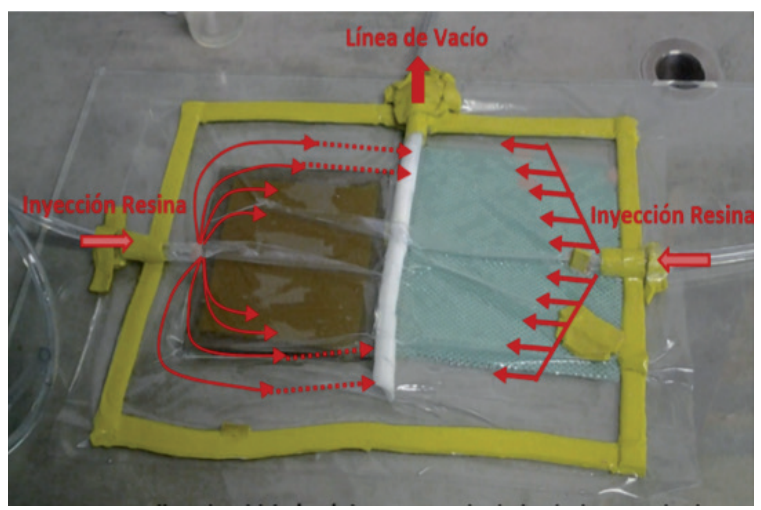

a) (left) 3 layers of Kevlar + Epoxy Resin; (right) 7 Layers of E-Glass fibers + Epoxy Resin

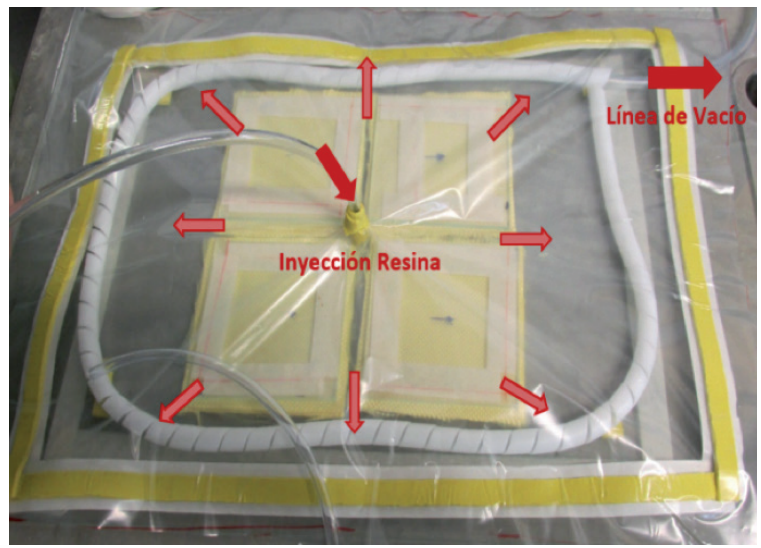

b) Infusion system to 4 samples manufacturing using a central feeding and a peripheral vacuum line: 3 layers of Kevlar + Epoxy Resin

materials: two samples of Spectra (HO-UHMW$\mathrm{PE}$ ) made by a Chinese manufacturer and one sample of Gold Shield (Aramid) manufactured by Honeywell (E.U.A). Table 1 shows some of the mechanical and physical properties of high performance fibers.

Notice that HMW-PE has the lowest density and an excellent combination between strength properties and toughness. The minimum diameters measured were around $13 \mu \mathrm{m}$ (Table 2). It is important to consider the possibly negative effect of the "knot" found in the Spectra Shield II - Thick as a manufacture defect (see Fig. 7). Fibers of the Spectra SR121 and Gold Shield have a homogenous diameter. The Diameter of the fibers is an important variable considered in the models developed to assess the elastic energy storage and to consider the effect of weight and cost in a final product.

\section{Nano-indentation Tests}

This kind of test was carried out to assess the magnitude of the elastic module (E) of the fibers

Fig. 6. Samples manufactured by infusion systems of Fig. 5: epoxy resin reinforced by Kevlar and glass fibers

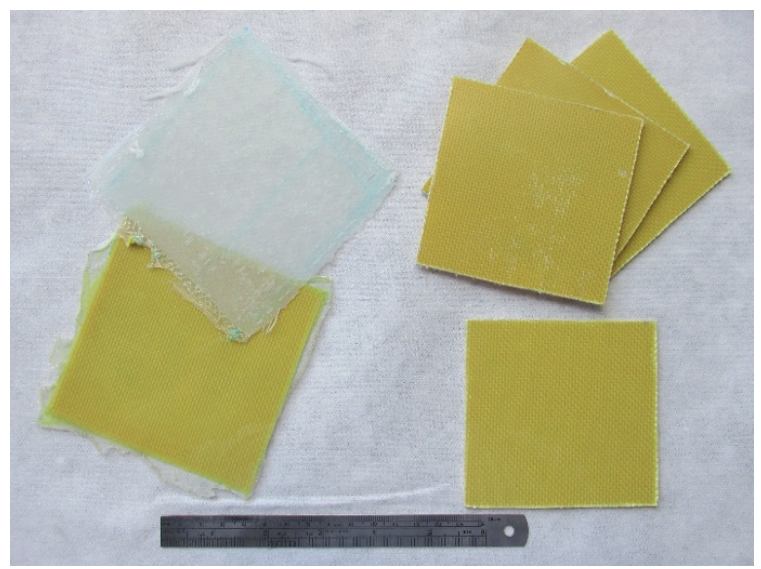

Table 1. Mechanical and physical properties of high performance fibres [16]

\begin{tabular}{|c|c|c|c|c|}
\hline Fibre Type & Fracture Resistance, GPa & Fracture Strain, x1000 & Axial Elastic Module, GPa & Density, $\mathrm{kg} / \mathrm{m}^{3}$ \\
\hline Aramid & $2,8-3,2$ & $15-45$ & $60-115$ & $1390-1440$ \\
\hline HMW-PE & $2,8-4,0$ & 29.38 & $90-140$ & $970-980$ \\
\hline LPC & $2,7-2,9$ & $33-35$ & $64-66$ & $1400-1420$ \\
\hline $\mathrm{PBO}$ & $5,4-5,6$ & $24-26$ & $270-290$ & $1540-1560$ \\
\hline PIPD & $3,9-4,1$ & $11-13$ & $320-340$ & $1690-1710$ \\
\hline Nylon & $0,06-0,08$ & $1500-2500$ & $1,0-1,5$ & $1070-1170$ \\
\hline S-Glass & $4,64-4,66$ & $53-55$ & $82-92$ & $2470-2490$ \\
\hline
\end{tabular}


Fig. 7. Cross-sections of samples of several laminates for inspection and mechanical characterization

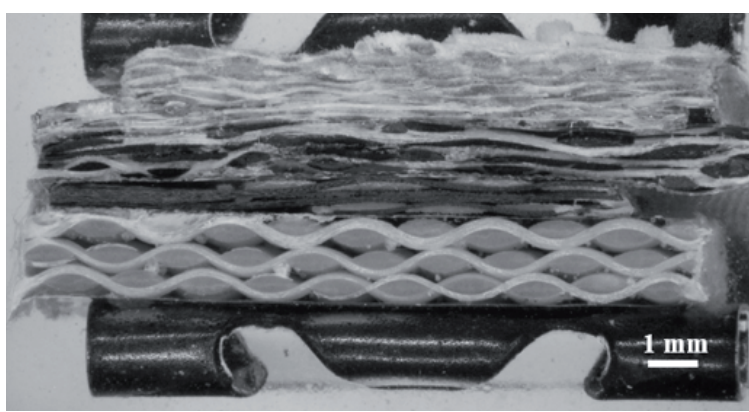

a) Laminate samples extracted for optical inspection and nanoindentation tests

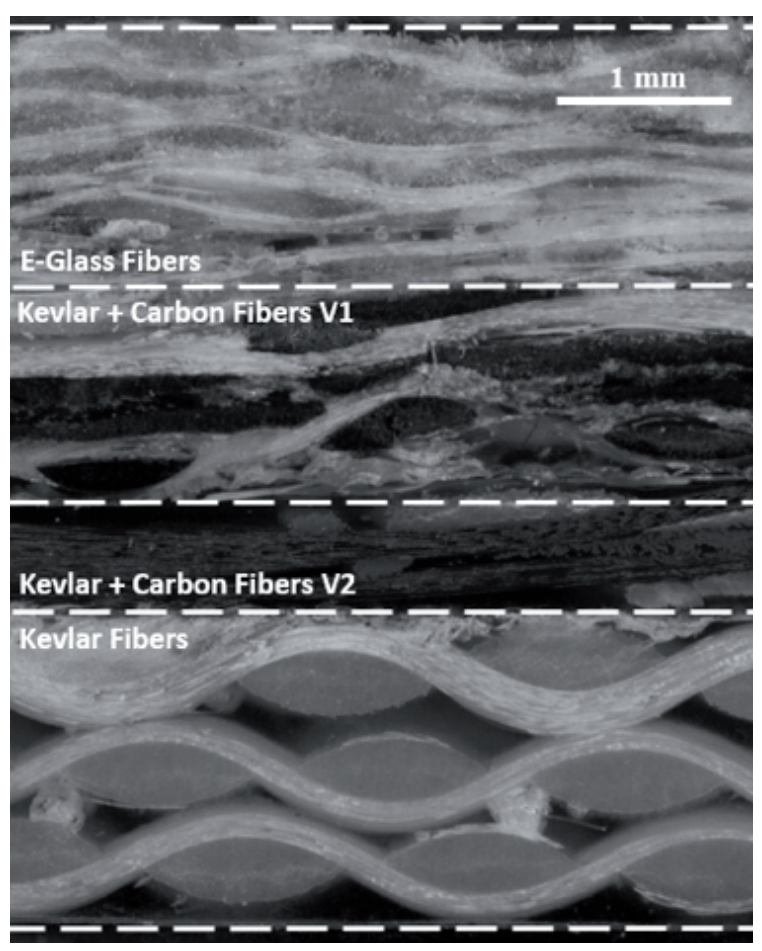

b) Stereo micrograph of a set of 4 samples of different configurations

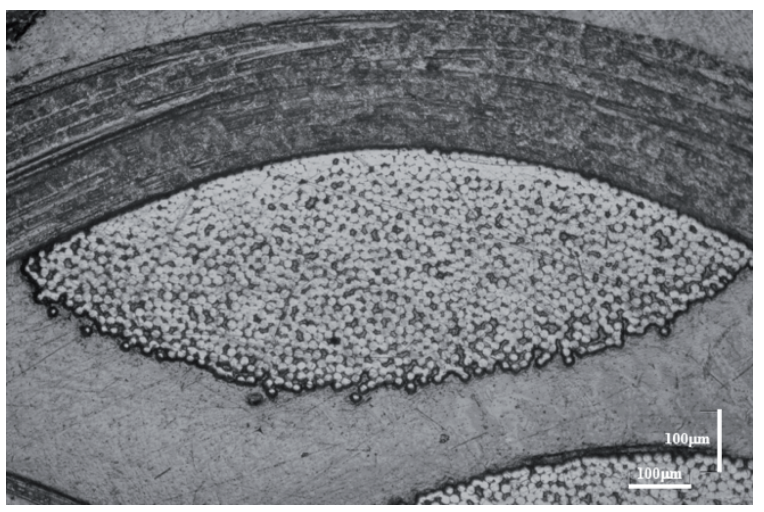

c) Detail of branches of Kevlar fibers (optical microscopy): longitudinal and cross views of fibers
Table 2. Average diameters of the analyzed fibers

\begin{tabular}{|c|c|c|}
\hline Laminate & Fiber & $\mathbf{D}_{\text {Fiber }}, \mu \mathrm{m}$ \\
\hline Gold Shield $\AA$ GV-2016 & Aramid & 13,0 \\
\hline Spectra Shield II - Thin & HMW-PE & 12,7 \\
\hline Spectra Shield - Thick & HMW-PE & 26,0 \\
\hline
\end{tabular}

(upon their cross section) and its radial variation at the interface between fibers and matrix. Measurements were carried out using an IBIS Nanoindentation System with a Berkovich indenter. Results of these measurements were plotted in the graphs of Fig. 9 for composites with the three basic types of fibers used in the manufacture of laminar composites shown in Fig. 7. Results of the values measured for $\mathrm{E}$ are in agreement with those reported in specialized literature. The horizontal axis is the penetration depth $\left(b_{t}\right)$.

\section{Microbardness}

The effect of the curing time and temperature time on the mechanical properties of a resin was explored using a polyester based resin prepared varying the weight percentage of its catalyst; see Fig. 10. Four days after the manufacturing of the samples microhardness was measured on the polished surfaces (red points); then, 24 days later the microhardness of the samples was measured (blue points). During this period the environmental temperature was between 21 to $28^{\circ} \mathrm{C}$. Finally, 11 days later, the curing of the samples was accelerated by using a furnace at $80^{\circ} \mathrm{C}$ for 5 hours to guaranty a complete curing. Microhardness was then measured again (purple points).

From Fig. 10, significant and systematic increases in hardness can be seen such as curing time and temperature increase. The curing agent also has an important role on the microhardness of the tested samples (the microhardness of some samples has risen more than twice in regard their initial values, red points). The last two curves (blue and purple curves) have almost the same slope, showing a decrease in hardness as $\mathrm{w} \%$ catalyst increases showing a different behavior of the hardness in regard to the initial curve (red points). It is important to bear in mind that for polymers the compressive yield stress can also 
Fig. 8. Geometrical details of the analyzed fibers
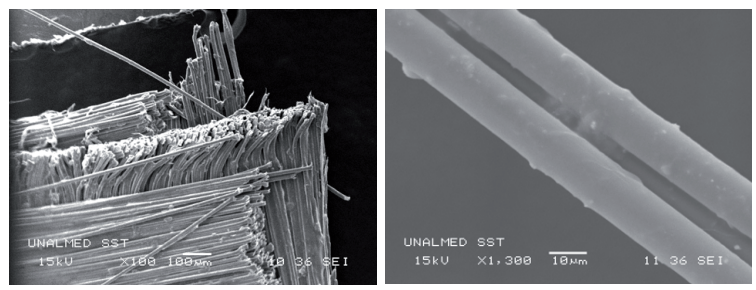

a) Aramid - Gold Shield
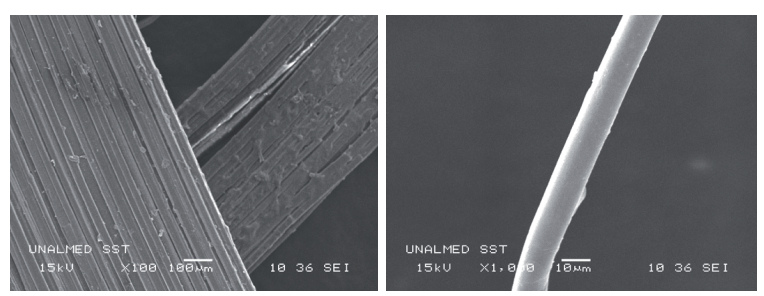

b) Spectra Shield II - SR1211 -Thin
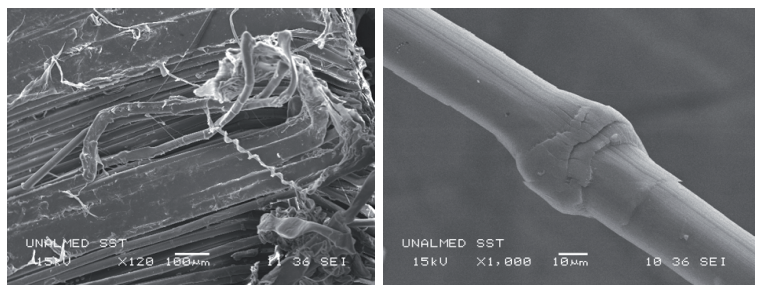

c) Spectra Shield II - Thick

be estimated from hardness measures $(\mathrm{Y} \approx \mathrm{H} / 3$, according to Tabor [40]).

We are currently obtaining extra-hard layers using alumina particles $\left(\mathrm{Al}_{2} \mathrm{O}_{3}\right)$ and others. The goal is to place some hard layers on or near the impact face of the armors to promote the activation of some additional dissipative mechanisms as the projectile abrasion (projectile peeling), plastic deformation of the projectiles, fracture of hard particles and the flow of these hard particles into the polymeric matrix.

The hardness of $\mathrm{Al}_{2} \mathrm{O}_{3}$ is about 1170 (94\% purity) to $1440 \mathrm{HV}$ ( $99.5 \%$ purity). In our composites, microhardness values up to $940 \mathrm{HV}$ have been measured in our samples using loads of $0.49 \mathrm{~N}(50$ grams). These values correspond to the hardness of a mixture of alumina particles and polymeric resin; that is why the lower values were recorded because of the lesser hardness of the matrix.

Using a comprehensive characterization method, developed in our group, we measured reaction kinetics using differential scanning calorimetry. The dynamic and dynamic-isothermal DSC data is used in combination with a Kamal-Sourour model for the reaction kinetics and cure. The models are integrated to find the Time-TemperatureTransformation diagram of the resin (see Fig. 11). The TTT diagram provides the processability window for each resin and aids the processing design towards optimization and control.

Fig. 9. Elastic Module (E) of the transverse section of fibers and its surroundings of anti-depth penetration matrix $\left(h_{t}\right)$.

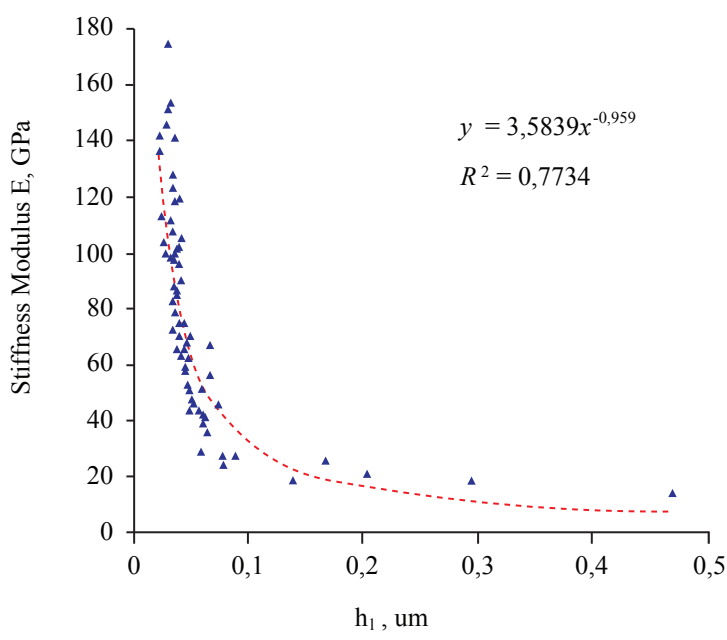

a) Sample B3: Carbon Fibers + Epoxy Resin

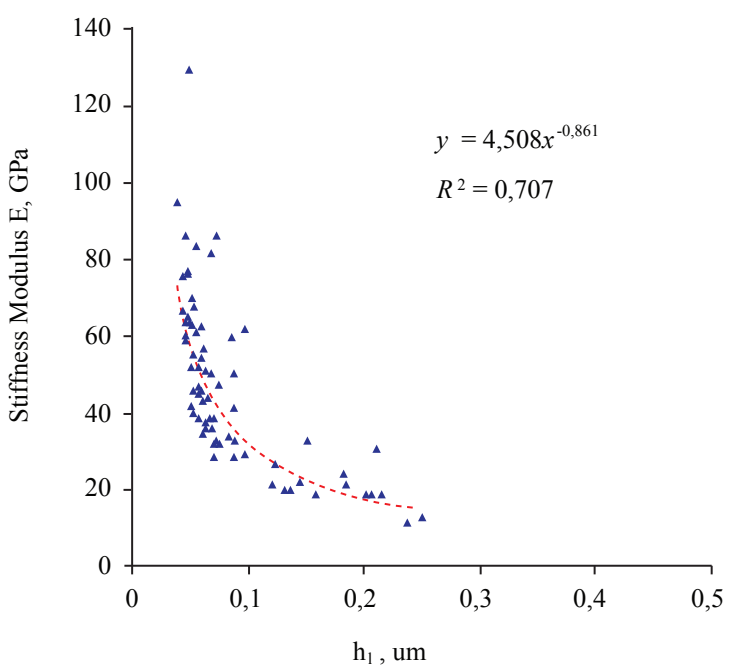

b) Sample B1: Glass Fibers + Epoxy Resin 


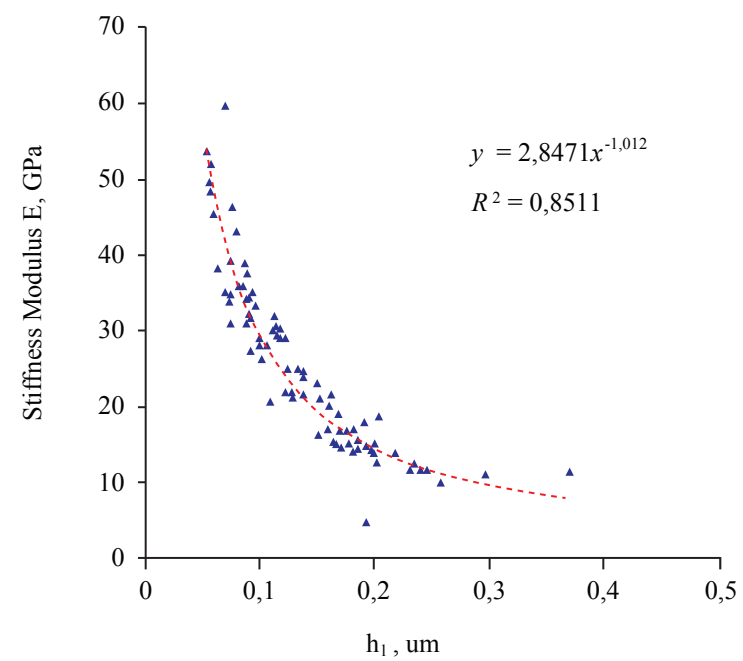

c) Sample B8: Kevlar Fibers + Epoxy Resin

\section{Conclusions}

A platform to design composite materials of polymeric matrix that are specifically for military applications on (as) fluvial and naval navigation (among others) has been developed. The platform integrates laminar composite materials design based on impact energy dissipation and temporary storage mechanisms with their manufacturing process (vacuum assisted infusion) and characterization (physical, mechanical and ballistic properties, geometry and integrity of the components and materials).

Fig. 10. Effect of curing time and temperature on hardness of the matrix. For each tested condition, each plotted point represents the average value of five measurements

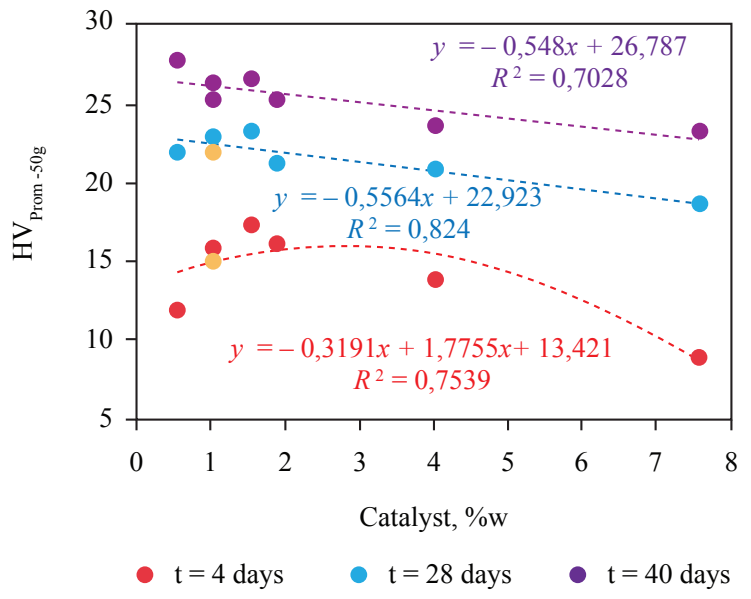

Fig. 11. Time-Temperature-Transformation diagram of the Epoxy resin

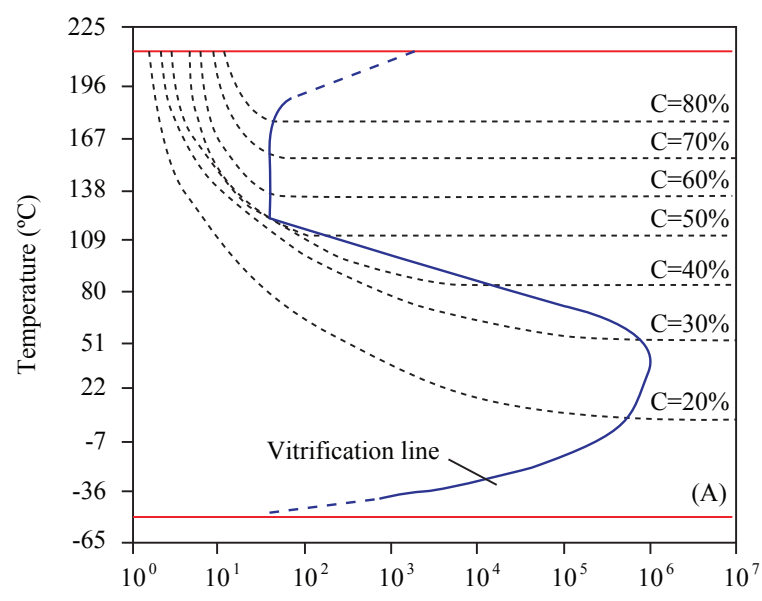

Log Time (min)

\section{Acknowledgments}

Authors want to thank Colciencias and Colfuturo (Convocatoria 528-2011) and Universidad Nacional de Colombia and Faro Tecnológico S.A.S. (Proyecto Hermes Nro. 27130) for its financial support. Also, they thank DynaComp S.A.S for the materials provided to manufacture some of the laminar composites for naval applications, the technical discussions and the assistance provided.

\section{References}

1. ZUKAS, J.A., NICHOLAS, T., SWIFT, H., GRESZCZUK, L.B., CURRAN, D.R. Impact Dynamics. John Wiley \& Sons, USA 1982, 452p.

2. SRIVATHSA, B., RAMAKRISHNAN, N. (1999). Ballistic performance maps for thick metallic armour. Journal of Materials Processing Technology 96, 81-91.

3. DEMIR, T., UBEYLI, M., YILDIRIM, R.O. (2008). Investigation on the ballistic impact behavior of various alloys against 7.62 $\mathrm{mm}$ armor piercing projectile. Materials and Design 29, 2009-2016. 
4. OZSAHIN, E., TOLUN, S. (2010). Influence of surface coating on ballistic performance of aluminum plates subjected to high velocity impact loads. Materials and Design 31, $1276-1283$.

5. OZSAHIN, E., TOLUN, S. (2010). On the comparison of the ballistic response of coated aluminum plates. Materials and Design 31, 3188-3193.

6. BØRVIK, T., FORRESTAL, M.J., HOPPERSTAD, O.S., WARREN, T.L., LANGSETH, M. Perforation of AA5083-H116 aluminium plates with conical-nose steel projectiles - Calculations. International Journal of Impact Engineering 36 (2009) 426-437.

7. BØRVIK, T.,CLAUSEN, A.H., HOPPERSTAD, O.S., LANGSETH, M. Perforation of AA5083-H116 aluminium plates with conical-nose steel projectilesexperimental study. International Journal of Impact Engineering 30 (2004) 367-384.

8. DEY, S., BØRVIK, T., HOPPERSTAD. O.S., LANGSETH, M. On the influence of constitutive relation in projectile impact of steel plates. International Journal of Impact Engineering 34 (2007) 464-48.

9. DEY, S., BØRVIK, T., HOPPERSTAD. O.S., LANGSETH, M. On the influence of fracture criterion in projectile impact of steel plates. Computational Materials Science 38 (2006) 176-191.

10. UBEYLI, M., DEMIR, T., DENIZ, H., YILDIRIM,R.O., KELES, O. Investigation on the ballistic performance of a dual phase steel against $7.62 \mathrm{~mm}$ AP projectile. Materials Science and Engineering A 527 (2010) 20362044.

11. MISHRA, B.,JENA,P.K., RAMAKRISHNA, B., MADHU, V., BHAT, T.B., GUPTA, N.K. Effect of tempering temperature, plate thickness and presence of holes on ballistic impact behavior and ASB formation of a high strength steel. International Journal of Impact Engineering 44 (2012) 17-28.

12. MEDVEDOVSKI, E. (2001). Wear-resistant engineering ceramics. Wear 249, 821-828.

13. NAIK, N.K., SHRIPAO, P., REDDY, B.C.K. (2006) Ballistic impact behaviour of woven fabric composites: Formulation. International Journal of Impact Engineering 32, 1521-1552.

14. HOO-FATT M.S., SIRIVOLU, D. (2010). A wave propagation model for the high velocity impact response of a composite sandwich panel. International Journal of Impact Engineering 37, 117-130.

15. REYES, G., CANTWELL, W.J. (2004). The high velocity impact response of composite and FML-reinforced sandwich structures. Composites Science and Technology 64, 35-54.

16. GRUJICIC, M., ARAKERE, G., HE, T., BELL, W.C., CHEESEMANB, B.A., YENB, C.F., SCOTT, B. (2008). A ballistic material model for cross-plied unidirectional UHMWPE fiber-reinforced armorgrade composites. Materials Science and Engineering A 498, 231-241.

17. Technical Guide Kevlar - Aramid Fiber. DuPond, 32p: www.kevlar.com.

18. LANE, R. High Performance Fibers for Personnel and Vehicle Armor SystemsPutting a Stop to Current and Future Threats. AMPTIAC Rome, NY: http://ammtiac. alionscience.com/pdf/AMPQ9_2ART01.pdf

19. Tawron - a versatile high-performance fiber. TEIJIN, 7p: http://www.teijinaramid.com/ aramids/twaron/

20. Technora. TEIJIN: http://www.teijinaramid. com/aramids/technora/

21. Honeywell Gold Shield ${ }^{\circledR}$ GV-2016: www. honeywell.com/spectra 
22. Dyneema: http://www.dyneema.com/ americas/applications/life-protection.aspx

23. POB Fiber Zylon. TOYOBO CO., LTD, 18p: www.toyobo.co.jp

24. MEDVEDOVSKI, EUGENE. Aluminamullite ceramics for structural applications. Ceramics International 32 (2006) 369-375.

25. MEDVEDOVSKI, EUGENE. Ballistic performance of armour ceramics: Influence of design and structure. Part 1. Ceramics International 36 (2010) 2103-2115.

26. MEDVEDOVSKI, EUGENE. Ballistic performance of armour ceramics: Influence of design and structure. Part 2. Ceramics International 36 (2010) 2117-2127.

27. KARAMIS, M.B. Tribology at high-velocity impact. Tribology International 40(2007) 98-104.

28. KARAMIS, M.B., NAIR, F., CERIT, A.A. The metallurgical and deformation behaviours of laminar metal matrix composites after ballistic impact. Journal of Materials Processing Technology 209 (2009) 4880-4889.

29. KARAMIS, M.B.s CERIT, A.A., NAI, F. Surface characteristics of projectiles after frictional interaction with metal matrix composites under ballistic condition. Wear 261 (2006) 738-745.

30. GAMA, B.A., GILLESPIE, J.W. Punch shear based penetration model of ballistic impact of thick-section composites. Composite Structures 86 (2008) 356-369.

31. XIAO, J.R., GAMA, B.A., GILLESPIE, J.W. Progressive damage and delamination in plain weave S-2 glass/SC-15 composites under quasi-static punch-shear loading. Composite Structures 78 (2007) 182-196.
32. ERKENDIRCI, O.F., (GAMA) HAQUE, B.Z. Quasi-static penetration resistance behavior of glass fiber reinforced thermoplastic composites. Composites: Part B xxx (2012) $\mathrm{xxx}-\mathrm{xxx}$

33. MORYE, S.S., HINE, P.J., DUCKETT, R.A., CARR, D.J., WARD, I.M. Modelling of the energy absorption by polymer composites. Composites Science and Technology 60 (2000) 2631-2642.

34. Lightweight ballistic composites - Military and Law enforcement applications. Edited by Ashok Bhatnagar. Woohead Publishing Limited, Cambridge, England, 2006, 428p.

35. SARVA, S., NEMAT-NASSER, S., MCGEE, J., ISAACS, J. The effect of thin membrane restraint on the ballistic performance of armor grade ceramic tiles. International Journal of Impact Engineering 34 (2007) 277-302.

36. QUN WANG, ZHAOHAI CHEN, ZHAOFENG CHEN. Design and characteristics of hybrid composite armor subjected to projectile impact. Materials and Design 46 (2013) 634-639.

37. CORRAN, R.S.J., SHADBOLT, P.J., RUIZ, C. Impact Loading of Plates - An Experimental Investigation. Int. J. Impact. Engng. Vol 1 No. 1 (1983) pp3-22.

38. Dey, S., Borvik, T., Teng, X., Wierzbicki, T., Hopperstad, O.S. On the ballistic resistance of double layered steel plates: An experimental and numerical investigation. International Journal of Solids and Structures 44 (2007) 6701-6723.

39. HOCKAUF, M., MEYER, L.W., PURSCHE, F., DIESTEL, O. Dynamic perforation and force measurement for lightweight materials by reverse ballistic impact. Composites: Part A 38 (2007) $849-857$. 
40. FLORES, A., ANIA, F., BALTÁ-CALLEJA, F.J. From the glassy state to ordered polymer structures: A microhardness study. Polymer 50 (2009) 729-746. 